\title{
Modelling Environmental Attitudes of the Users of Kilombero Valley Wetlands, Tanzania
}

\author{
Felister Mombo ${ }^{1,2}{ }^{*}$, Zuzanna Pieniak ${ }^{2}$, Valerie Vandermeulen ${ }^{2}$ \\ ${ }^{1}$ Department of Forest and Environmental Economics, Sokoine University of Agriculture, Morogoro, Tanzania \\ ${ }^{2}$ Department of Agricultural Economics, Faculty of Bioscience Engineering, Gent University, Gent, Belgium

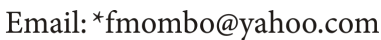

How to cite this paper: Mombo, F., Pieniak, Z. and Vandermeulen, V. (2016) Modelling Environmental Attitudes of the Users of Kilombero Valley Wetlands, Tanzania. Journal of Water Resource and Protection, 8, 1078-1089.

http://dx.doi.org/10.4236/jwarp.2016.812085

Received: June 17, 2016

Accepted: October 30, 2016

Published: November 2, 2016

Copyright $\odot 2016$ by authors and Scientific Research Publishing Inc. This work is licensed under the Creative Commons Attribution International License (CC BY 4.0).

http://creativecommons.org/licenses/by/4.0/

(c) (i) Open Access

\begin{abstract}
Development policies have for a long time made it more profitable for people to degrade than to conserve environment. The adoption of these economic wide policies by Africa especially during colonial time and after independence has resulted into erosion of its communities' conservation behaviour and attitude. Although many studies assess environmental attitudes, those focussing on African regions or countries using New Environmental Paradigm (NEP) scale are very limited. Such studies in the African context using NEP scale are very important, simply because many people depend on the environment for their livelihood, and in the process they destroy the world's valued ecosystems including wetlands. This study is meant to fill in the gap using Kilombero valley wetlands in Tanzania as a case. The study used Structural Equation Modelling (SEM) to predict the behaviour of the users based on attitudes, environmental knowledge and awareness. The findings indicate that users of the Kilombero wetlands have a generally positive attitude towards the environment, despite a great degree of variability among the study participants. The study shows also that a certain level of environmental awareness is needed in order to increase people's knowledge about environmental issues and change their environmental attitudes. The NEP scale does not fully fit into the Tanzanian context, thus suggesting that further research into the adaptation of the scale is needed.
\end{abstract}

\section{Keywords}

Modelling Environmental Attitudes, Awareness, Knowledge, NEP-Scale

\section{Background}

There is a plethora of development policies, which for a long time have made it more profitable for people to degrade than to conserve environment [1]. The degradation is a result of mis-management of ecosystems which has lead to improper uses of Ecosystems 
Services in the global societies. Sometimes overuse or misuse of environmental resources results into unsustainable ecosystems management [2]. The problem is very common among Africa's ecosystems especially in the wetlands on which local communities primarily depend for their livelihoods [3]. These environmental problems to most African communities are considered to be a result of deterioration of traditional local institutions which, prior to the advent of colonialism, were concerned with the conservation of natural environment [4] [5] [6]. Most African communities' conservation attitudes and behaviours were an integral part of the communities' culture. The introduction of classical economic principles adopted by most African governments after independence continued to dismantle the few existing traditional institutions concerned with natural environment conservation [7] [8]. The new concept of sustainable development (henceforth SD) has been incorporated into many levels of society [9]. Scholars have been arguing for a standard definition of the concept and no consensus has been reached; instead interpretation of the concept depends on who defines it. Brundtland Commission in 1990s [2] [10] provided the commonly used definition of the term.

The progressive persuasion of the sustainability perspective has also made the environmental psychology to shift its main focus of observation to a number of ecologically relevant behaviours and to the constructs and processes that are assumed to underlie these behaviours. These constructs are assumed to connect individual and locally practised environmentally relevant behaviours with the possible social-perceptual systems of personal orientation toward the environment. On the other hand, the constructs are assumed to provide intra-individual and inter-situational stability to the related environmental behaviours and thereby allow their pre-visualization [11].

Psychologists and social scientists have developed scales of measuring people's perceptions and behaviours on SD. According to [12], amongst the Environmental Attitude (EA) measures available, only three have been widely used namely the Ecology Scale, the Environmental Concern Scale and the New Environmental Paradigm (NEP) Scale. One of the three world tested scales and recently revised to include some of the more recent orientations of the SD perspective is New Environmental Paradigm [13] [14]. In the NEP scale, the ecologically sound worldviews refer to various aspects such as the existence of limits in the availability and use of natural resources by humans, the fragility of the so-called "natural balances", and the need for human activities to value natural resources for their own sake rather than for exclusive human purposes [11].

This study aimed at testing the relevance of this revised NEP scale in the Africans' cultural context using Tanzanian's community. The EA studies in low economic countries and specifically in Africa are scarce; and only a few of them have used NEP scale in studying environmental behaviours and perceptions [12] [15]. What we know is that scale has been used only in South Africa, which cannot be considered enough to make any conclusions on Africans' perceptions and behaviours on environmental world views. [12] reveal that samples from different socio-economic backgrounds may respond differently to the NEP Scale; thus it may even be necessary to develop measures of EA that address more adequately the concerns of blue-collar samples from low income areas. 
Previous studies [16] [17] reveal that ecological behaviour cannot be considered as simply resulting from a rational choice. Emotional factors also play an important role. Therefore, it may be assumed that ecological behaviour in Africa, and for this case Tanzania, is a lower involvement in the decision process, characterised by much more emotional than rational motives. Hence, we assume that awareness and attitudes will positively be associated with knowledge which is in itself, an important factor in decisionmaking [18] [19]. Thus, people with sufficient knowledge on rules and regulations on environmental issues are expected to behave in a manner that can have an impact on the sustainability of the region. Additionally, following the classical attitude-behaviour theory [20] environmental attitude may have an impact on people's behaviour regarding environmental issues.

\section{Conceptual Frame Work}

The conceptual framework of the study (Figure 1) shows the expected relationships between attitudes, knowledge and awareness in the case of environmental issues. These three concepts will lead to behaviour and action with an impact on the environment. However, behaviour is outside the scope of the current study and is therefore circled by a dotted line.

Further to this, parameter "awareness" will also help to inform users on how the Non-Governmental Organizations (NGOs) works in environmental awareness creation, in influencing such peoples' behaviour and attitudes. These institutions normally take into account the globally most agreed concepts of sustainability. The knowledge on this aspect would thus help the policy making process on how the multi-varied groups of wetlands ecosystems resource users can be brought together; and that they would have a common understanding when it comes to management issues on these important wetlands of the world (Kilombero Valley) listed as Ramsar site. This would also add knowledge into conservation education in relations to behaviour and attitudes in Africans' global commons governance.

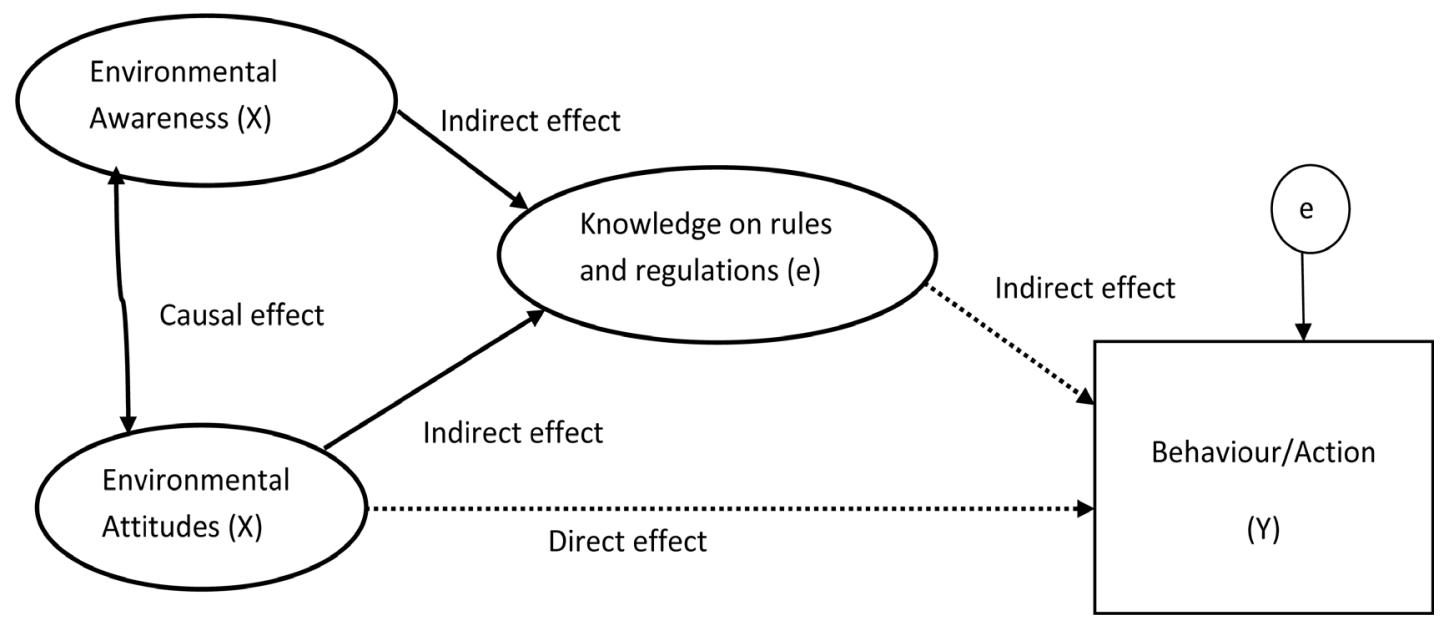

Figure 1. Conceptual model and SEM path specifications. 


\section{Methodology}

\section{Study Area}

The research focused on the communities in and around Kilombero Valley Wetlands in Morogoro region, South-East of Tanzania. These wetlands have been designated as a Ramsar site since 2002, recognizing their international importance. The wetlands are located between Latitude $70^{\circ} 40^{\prime}$ to $90^{\circ} 7^{\prime}$ South and Longitude $350^{\circ} 37^{\prime}$ to $300^{\circ} 00^{\prime}$ East (Figure 2). The valley lies between the Udzungwa Mountains and the Mahenge escarpment forming part of Eastern Arc Mountains listed by Convention on Biological Diversity (CBD) as amongst the 20 world's biodiversity hot spot area. The valley is divided by the Kilombero River and falls within the districts of Kilombero and Ulanga. The two districts of Kilombero and Ulanga were chosen due to the fact that Kilombero valley lies between the two. The Morogoro Municipal was chosen to represent the urban dwellers that are regarded as secondary users of the wetlands. The total population living in the Morogoro region is 1.7 million of which $12 \%$ is living in the Morogoro district, $19 \%$ in the Kilombero district and $11 \%$ in the Ulanga district. About $83 \%$ of the population of the Kilombero and Ulanga districts live in the Ramsar site, namely 430,135 people [21].

\section{Method}

\section{Sampling procedure}

The target populations for this study were households in Kilombero, Ulanga and Morogoro urban districts. A mult-stage sampling procedure was applied to select the sample. For the villages and streets, purposive sampling technique was applied where the selection of these was determined through various criteria depending on the site location. In the rural areas, economic activities of the communities were used to identify villages that were to be included in the study. Such households' common economic

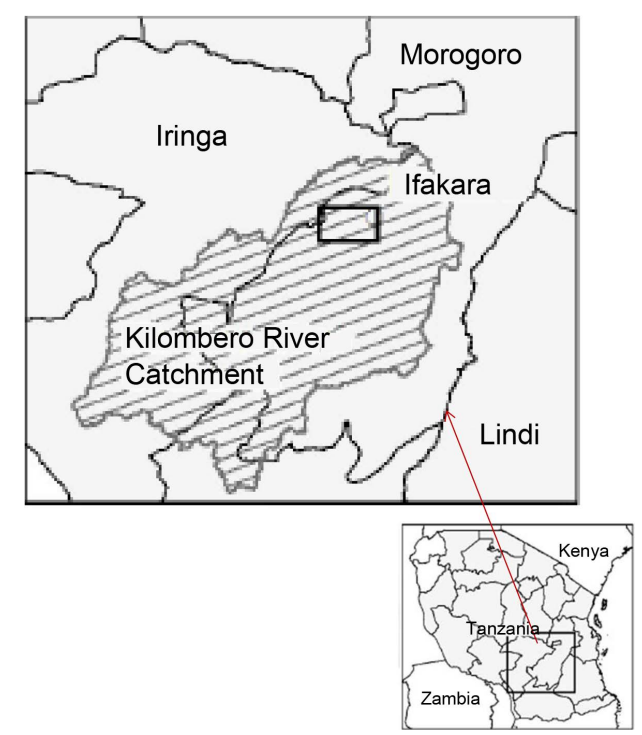

Figure 2. Map of Kilombero valley wetlands. Source: Hardy et al. (2014) with minor modification. 
characteristics include having a big number of livestock farmers, fishermen, and crop famers. In Urban areas two criteria were used to purposively select the streets; some of such criteria were education and income levels of most of the residents in that particular street. This was because in urban areas people distribution is usually along these characteristics. A total of 20 villages and 10 streets were purposively selected.

The sampling frame was a list of all households in all purposively selected villages and streets in Kilombero; Ulanga and Morogoro urban where the Kilombero and Ulanga districts respondents represented the rural population and Morogoro urban represented the urban population. Simple random techniques were applied using the update village/street registers form to select 408 households which participated in the interview. The interview was on face to face basis where only heads of the households were invited. A male or female head was purposefully selected after a random pick of a household. The invited house heads were given an invitation letter which specifically mentioned a female or male head to get equal representation of male and female respondents. Moreover in case one of the identified head was not available the letter asked for the available head to be interviewed, village/street executives were used to assist in this exercise. The sample consisted of people from diverse economic activities such as businessmen, formal employees, small business vendors and farmers. Most respondents $(60 \%)$ had at least primary education, only $4 \%$ completed adult education and $20 \%$ completed secondary education. The remaining $26 \%$ had higher education degrees. Majority (52\%) had an income of between 100,000 and $1 \mathrm{TZS}^{1}$ Millions (M) per annum. Gender distribution was nearly even, with male respondents constituting $58 \%$ of the sample. The respondent's age ranged from 17 to 81 years.

In a survey, a structured questionnaire was administered face-to-face using Kiswahili language. The revised NEP scale of [13] was used in the questionnaire to measure environmental attitudes. The scale statements were translated from original English language to Kiswahili with consultation from Baraza la Kiswahili Tanzania (BAKITA). However during the pretesting, some of the Kiswahili registered statements were well understood by the natives and therefore the formally educated natives were used to put the context right. All participants were conversant with Kiswahili language. Participants were asked to give their opinions on a 5-point Likert scale ranging from (1) strongly disagree to (5) strongly agree. During the pretesting of the questionnaire, some of the original items were miss-conceived by the participants who believed that the results would be used by the government as an excuse to remove them from areas where they were using to meet their basic needs such as grazing their stocks; cultivating their crops and extracting materials from forests. Therefore, five items were deleted ${ }^{2}$ and not included in the further analysis. Table 1 shows the included 5 pro-NEP and 5 anti-NEP items.

${ }^{1}$ TZS Tanzanian shilling, at time of data collection the exchange rate was 1 US $\$=1450$ TAS.

${ }^{2}$ The following statements were deleted: when humans interfere with nature, it often produces disastrous consequences; humans are severely abusing the environment; despite our ability humans are still subject to the laws of nature; humans have the right to modify the natural environment to suit their needs; the earth has plenty of natural resources if we just learn how to develop them. 
Table 1. NEP scale item response frequencies and descriptive statistics.

\begin{tabular}{|c|c|c|c|c|c|c|c|c|}
\hline & NEP statement & $\begin{array}{c}\text { Strongly } \\
\text { Disagree (\%) }\end{array}$ & $\begin{array}{l}\text { Disagree } \\
\quad(\%)\end{array}$ & $\begin{array}{l}\text { Neutral } \\
(\%)\end{array}$ & Agree (\%) & $\begin{array}{l}\text { Strongly } \\
\text { agree }(\%)\end{array}$ & Mean & $\begin{array}{l}\text { Standard } \\
\text { Dev. }\end{array}$ \\
\hline 1 & $\begin{array}{l}\text { The so called "ecological crisis" facing human kind has been greatly } \\
\text { exaggerated }\end{array}$ & 30.6 & 23.6 & 6.8 & 22.8 & 16.3 & 2.71 & 1.50 \\
\hline 2 & $\begin{array}{l}\text { If things continue on their present course we will soon experience a } \\
\text { major ecological catastrophe }\end{array}$ & 2.5 & 3.0 & 5.5 & 49.3 & 39.8 & 4.21 & 0.87 \\
\hline & $\begin{array}{l}\text { Humans will eventually learn enough about how nature works to be } \\
\qquad \text { able to control it }\end{array}$ & 10.8 & 7.8 & 7.3 & 51.0 & 23.3 & 3.68 & 1.22 \\
\hline 4 & The balance of nature is very delicate and easily upset & 7.0 & 8.6 & 10.1 & 48.6 & 25.7 & 3.77 & 1.13 \\
\hline 5 & Humans were meant to rule over the rest of nature & 9.9 & 8.7 & 4.8 & 43.6 & 32.9 & 3.81 & 1.26 \\
\hline 6 & Plants and animals have as much right as humans to exist & 4.8 & 4.0 & 1.5 & 40.1 & 49.6 & 4.26 & 1.02 \\
\hline 7 & $\begin{array}{l}\text { Human ingenuity will ensure that we do not make the earth } \\
\text { un-habitable }\end{array}$ & 15.4 & 13.9 & 7.6 & 37.7 & 25.3 & 3.44 & 1.40 \\
\hline 8 & $\begin{array}{l}\text { We are approaching the limit of the number of the people the earth } \\
\qquad \text { can support }\end{array}$ & 23.8 & 25.8 & 15.5 & 20.3 & 14.5 & 2.76 & 1.39 \\
\hline 9 & $\begin{array}{l}\text { The balance of nature is strong enough to cope with the impacts of } \\
\text { modern industrial nation }\end{array}$ & 26.4 & 27.4 & 11.4 & 24.4 & 10.4 & 2.65 & 1.37 \\
\hline & The earth is like a spaceship with very limited room and resources & 16.2 & 17.7 & 12.7 & 33.7 & 19.7 & 3.23 & 1.38 \\
\hline
\end{tabular}

Note: agreement with the five even-numbered items and disagreement with the five odd-numbered items indicate pro-NEP responses. Hypothesized facets: reality of limits to growth (items 8 and 10); anti-anthropocentrism (items 5 and 6); fragility of nature's balance (items 4 and 9); rejection of exemptionalism (items 3 and 7); possibility of an ecological crisis (items 1 and 2).

The questionnaire furthermore included items related to environmental awareness. Participants were asked whether they are aware of the meaning of biodiversity, wetlands, environmental degradation, environmental conservation and global warming. This was measured using four response categories: 1) I don't know it, 2) I heard this term before, 3) I know what it is and 4) I can explain.

Lastly, the questionnaire included items on knowledge on the rules and regulations. Participants were asked to self-score their level of knowledge with respect to some specific policies and legal statements ${ }^{3}$. Again, four response categories were used: 1) I don't know it, 2) I heard this statement before, 3) I somehow know what it is and 4) I surely know what it is.

\section{Analysis}

The data were analysed using the statistical software SPSS version 16.0 and LISREL 8.72. Due to a high number of missing values, three cases have been excluded from the analysis resulting into 405 valid cases. Structural equations model parameters have been estimated and the general fit of the model has been assessed using the robust maximum likelihood procedure in LISREL 8.72. With the use of structural equation modelling (SEM), the examination of all the relationships between constructs and items was performed simultaneously, which is a substantial advantage compared with single equation modelling [22]. To evaluate the fit of the model, the $\chi^{2}$-value together with degrees of ${ }^{3}$ The statements relating to legislation were: wetlands are not supposed to be occupied as they are hazarders areas; all areas length of $60 \mathrm{M}$ around river banks are prohibited from any use; no any development work can be carried on without doing Environmental Impact assessment; any person shall not graze any livestock in a game reserve or wetlands reserve; any person shall not fish in water controlled areas without permission. 
freedom are reported, as well as three other indices: the Root Mean Square Error of Approximation (RMSEA), the Goodness of Fit Index (GFI) and the Comparative Fit Index (CFI). Values below 0.08 for RMSEA [23] and above 0.90 for GFI and CFI [22] indicate an acceptable fit of the model.

The mathematical expression of the model is in this form;

$$
Y=a X+e
$$

where; $Y$ is an endogenous variable that appear once as the dependent variable of the equation.

For this case the dependent variable is Behaviour/Action.

$X$ is the independent variable that appears on the right hand side of the equation, known as exogenous/given variables. For this case the independent variables are environmental attitudes, environmental awareness and knowledge on rules and regulations.

$a$ is the weighting coefficient

$\boldsymbol{e}$ is the Latent variable which is not directly measured

The independent variable $(\boldsymbol{X})$ may have a direct or indirect effect with the dependent variable $(Y)$. In our case, the environmental awareness had a direct effect with behavior/action, while other variables such as environmental awareness and knowledge on rules and regulations had indirect effect with the dependent variable. Besides, knowledge on rules and regulations acts as a mediator between environmental attitude or environmental awareness and behaviour/action implying that, environmental attitude and environmental awareness influence behavior/action through knowledge on the rules and regulation. Further, there is a correlation between environmental attitude and environmental awareness, meaning that these independent variables influence each other to affect the dependent variable (behavior/action).

To evaluate the fit of the model, the $\chi^{2}$-value together with degrees of freedom are reported, as well as three other indices: the Root Mean Square Error of Approximation (RMSEA), the Goodness of Fit Index (GFI) and the Comparative Fit Index (CFI). Values below 0.08 for RMSEA (Browne and Cudeck, 1993) and above 0.90 for GFI and CFI (Bollen, 1989) indicate an acceptable fit of the model.

\section{Results}

The statements and their associated means and standard deviations are presented in Table 1. From this table, it can be seen that the highest means (4.21 and 4.26) are obtained on two statements, namely "if things continue on their present course, we will soon experience a major ecological catastrophe" and "plants and animals have as much rights as humans to exist". Surprisingly, the other item on anti-anthropocentrism, which was formulated as an anti-NEP item, namely "humans were meant to rule over the rest of nature", also received a high average score (3.81).

After recoding the environmental concern items in accordance with pro-environmental attitudes, the overall attitude score was calculated by taking the average of all the responses. This resulted into a mean of 3.19 and a standard deviation of 1.25. This can be regarded as a moderately positive attitude towards environmental issues (3.19 
out of a possible 5), while the relatively large standard deviation indicates much variability among the participants.

The hypothesised model, which relates attitudes with awareness and knowledge, performed well (Figure 2). The $\chi^{2}$ for the model was 199.21 with 113 degrees of free$\operatorname{dom}(\mathrm{p}<0.001)$. The RMSEA value was 0.043 ; the NFI was 0.93 , the GFI was 0.94 and the CFI was 0.97 , indicating that the goodness-of-fit indices were satisfactory. The $\mathrm{R}^{2}$ value for model explaining knowledge on rules and regulations was 0.39 ; thus the hypothesised constructs account for $39 \%$ of the variance in reported knowledge on environmental rules and regulations.

Environmental awareness was positively, relatively strong and directly associated with knowledge on rules and regulations. Furthermore, awareness was positively associated with environmental attitudes. Thus, people who were more aware about the environment reported stronger endorsement of NEP beliefs and higher knowledge on rules and regulations. Environmental attitudes had a relatively weak relationship with knowledge about rules and regulations.

\section{Discussion and Conclusions}

Our first objective was to explore how the environmental attitudes in the Kilombero valley wetland, Tanzania, match to those of the rest of the world. We found that in the case of Tanzania, the results are not always consistent with what [24] found in his study on Chinese attitudes and to that of [25] on Brazilian, Czech, German, Indian, Russian, and New Zealand attitudes on environmental conservation. In the mentioned authors' studies, people did not show a great variation in attitudes (an average positive value with a small standard deviation) as compared to that what our study revealed. This means that although the average environmental attitude in our study is moderately positive just like in these other studies, the large standard deviation shows that there is a great degree of variability in the attitudes amongst people in Tanzania. Common understanding is one of the prerequisite in collective action responsibility required in the management of common pool resources. Ecosystems such as wetlands and environment are one of the global commons that require collective action responsibilities [26] [27] [28]. This suggests the existing variations in the Tanzania society's attitudes could have negative implication to the management of the global commons.

Society's interactions with land and landscape such as wetlands shape their perception and attitudes towards land values and uses [29]. The author argues that land and landscape are perceived differently among groups of people. The perception depends on to what extent there is direct and indirect use and also the benefits to society of their interactions with the land. Although land has traditionally considered as supporting basic human needs for shelter, food and fibre. It has also increasingly become a resource to be exploited by landowners for economic gain, through various forms of development and resource extraction as well as food, fibre and timber production [3]. Different from people in Tanzania, the vast majority of the public in UK for example have become increasingly separated from direct involvement with the land itself. In the 
UK only a relatively small proportion of the population, including farmers, own or actively manage land [29]. People who have a predominantly functional perspective of land regard it as a productive resource which is a case for the most of public in Tanzania where $80 \%$ of the population reside in rural and are primarily dependent on land and natural environment for their basic needs of food, shelter and fibres [3]. The introduction of SD principles through establishment of a Ramsar site poses some constraints to the Kilombero Valley wetlands beneficiaries since the land and landscape (the valley and its catchment areas) was before used for other economic activities such as fishing, crop cultivation, extraction of timber and livestock rearing. [30] in his study on attitudes and land use behaviour in USA found out a significant variations in conservation attitudes among categories of people depending on their socio-economic characteristics. The author postulate that a landowner faced with a conflict between the conservation goals of society, and his or her own property interests determine the behaviour by his/her perceptions where some may find a way to compromise, to meet their own goals as well as those of society. Consequently the big variations existing among the Kilombero wetlands stakeholders could result from their socio-economic characteristics. These characteristics certainly have an implication to the sustainability of the particular wetlands which are listed as a Ramsar site. For the realization of SD objective concerning this Ramsar site such existing variations should be dealt with in order to bring about collective responsibility.

Moreover, several items of the NEP scale do not seem to be useful in the specific context of our study. Especially the anti-anthropologic items seem to be contradictory answered within the sample. Most people agreed with both statements on anti-anthropocentrism included. However, one was formulated in a pro-NEP manner (Plants and animals have as much right as humans to exist) and the other in an anti-NEP manner (Humans were meant to rule over the rest of nature). This result suggests that it should be further investigated whether the NEP scale can be used in developing countries, such as Tanzania, or whether adaptations should be made.

Our second objective was to analyse whether environmental awareness and people's environmental attitudes are associated with their knowledge on rules and regulations. The estimated model showed that this is true and thus people who were more aware about the environment held more positive environmental attitudes and higher knowledge on rules and regulations. However, the relationship between awareness and knowledge was much stronger than between knowledge and attitudes meaning that a certain level of awareness needs to be created in order to increase people's knowledge as well attitudes in relation to environmental issues (Figure 3). Higher knowledge and more positive attitudes are then expected to have a direct impact on people's behaviour, thus they are expected to perform action that can have an impact on the sustainability of their region.

This study faces a limitation. It focused only on peoples' awareness, attitudes and knowledge, without investigating the actual behaviour. We admit that the model estimated in this study may not be complete, which is suggested by its $\mathrm{R}^{2}$ value. Future research investigating the impact of additional determinants, e.g. perceptions and beliefs 


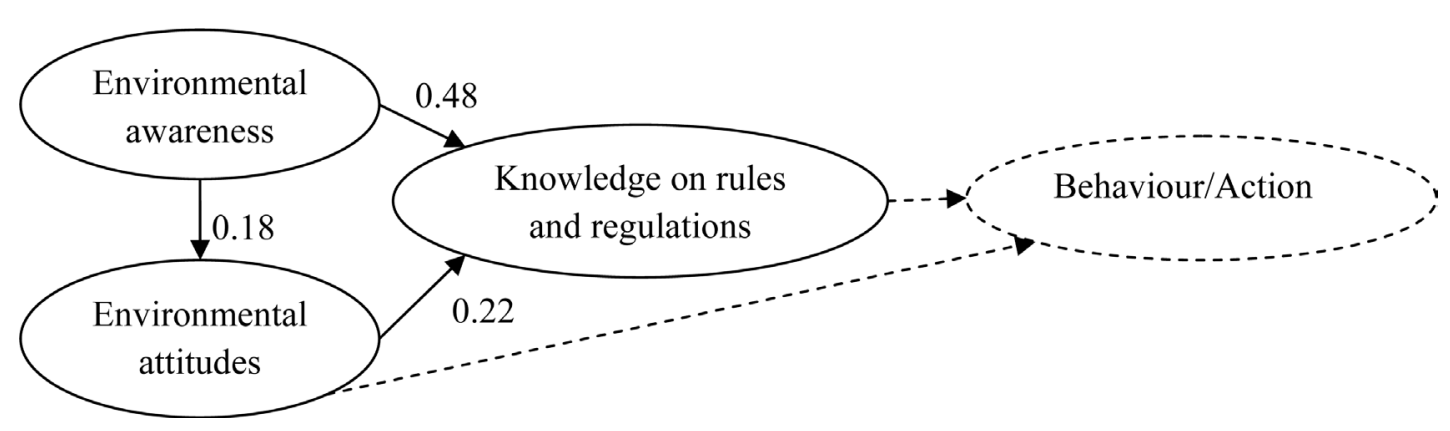

Figure 3. Awareness, attitudes, knowledge and behaviour model in the case of environmental issues.

as affective determinants, together with the more cognitive factors, such as awareness explored in the study is recommended.

\section{Acknowledgements}

To the communities in and around the Kilombero Valley Wetlands; you are greatly appreciated for without your personal sacrifices in terms of the time and information given to us it would never have been possible for the authors to write this article.

\section{References}

[1] MA (Millennium Ecosystem Assessment) (2005) Ecosystems and Human Well-Being. Synthesis. Island Press, Washington.

[2] Pearce, W.D. and Tunner, R.K. (1990) Economics of Natural Resources and the Environment. BPCC Wheatons Ltd, Exeter, Britain.

[3] Emerton, L. (2005) Values and Rewards: Counting and Capturing Ecosystem Water Services for Sustainable Development. IUCN Water, Nature and Economics Technical paper number 1. World Conservation Union (IUCN), Ecosystems and Livelihoods Group Asia. IUCN, Gland, Switzerland.

[4] Kajembe, G.C. and Wiersum, K.F. (1998) Bridging the Gap between Indigenous Initiatives and Externally Sponsored Forestry Interventions. In: Chamshama, S.A.O., Ed., First Annual Forestry Research Workshop, Sokoine, Morogoro, Tanzania, 95-105.

[5] Maganga, F.P. (2002) The Interplay between Formal and Informal Systems of Managing Resource Conflicts: Some Evidence from South-Western Tanzania. The European Journal of Development Research, 14, 51. http://dx.doi.org/10.1080/714000424

[6] Kajembe, G.C. (1994) Indigenous Management Systems as a Basis for Community Forestry in Tanzania: A Case Study of Dodoma Urban and Lushoto Districts. Wageningen Agricultural University, Netherlands, p. 1941.

[7] Leach, M., Mearns, R. and Scoones, I. (1999) Environmental Entitlements: Dynamics and Institutions in Community-Based Natural Resources Management. World Development, 27, 225. http://dx.doi.org/10.1016/S0305-750X(98)00141-7

[8] Saleth, R.M. and Dinar, A. (2004) The Institutional Economics of Water: A Cross-Country Analysis of Institutions and Performance. Edward Elgar Publishing, Cheltenham, UK, Northampton, MA, USA. http://dx.doi.org/10.1596/0-8213-5656-9

[9] Ness, B., Urbel-Piirsalu, E., Anderberg, S. and Olsson, L. (2007) Categorising Tools for Sustainability Assessment. Ecological economics, 60, 498-508.

http://dx.doi.org/10.1016/j.ecolecon.2006.07.023 
[10] Elliot, J. (2006) An Introduction to Sustainable Development. 3rd Edition, Routledge, New York.

[11] Corral-Verdugo, C.G., Bonnes, M., Moser, G. and Sinha, J.B.P. (2008) Environmental Beliefs and Endorsement of Sustainable Development Principles in Water Conservation: Toward a New Human Interdependence Paradigm Scale. Environment and Behavior, 40, 703. http://dx.doi.org/10.1177/0013916507308786

[12] Hawcroft, L.J. and Milfont, T.L. (2010) The Use (and Abuse) of the New Environmental Paradigm Scale over the Last 30 Years: A Meta-Analysis. Journal of Environmental Psychology, 30, 143-158. http://dx.doi.org/10.1016/j.jenvp.2009.10.003

[13] Dunlap, R.E., Van Liere, K.D., Mertig, A.G. and Jones, R.E. (2000) Measuring Endorsement of the New Ecological Paradigm: A Revised NEP Scale. Journal of Social Issues, 56, 425-442. http://dx.doi.org/10.1111/0022-4537.00176

[14] Steg, L., Dreijerink, L. and Abrahamse, W. (2005) Factors Influencing the Acceptability of Energy Policies: A Test of VBN Theory. Journal of Environmental Psychology, 25, 415-425. http://dx.doi.org/10.1016/j.jenvp.2005.08.003

[15] LaLonde, R. and Jackson, E.L. (2002) The New Environmental Paradigm Scale: Has It Outlived Its Usefulness? The Journal of Environmental Education, 33, 28-36. http://dx.doi.org/10.1080/00958960209599151

[16] Kals, E., Schumacher, D. and Montada, L. (1999) Emotional Affinity toward Nature as a Motivational Basis to Protect Nature. Environment and Behavior, 31, 178-202.

[17] Vining, J. (1992) Environmental Emotions and Decisions: A Comparison of the Responses and Expectations of Forest Mangers, an Environmental Group, and the Public. Environment and Behavior, 24, 3-34.

[18] Alba, J.W. and Hutchinson, J.W. (1987) Dimensions of Consumer Expertise. Journal of Consumer Research, 13, 411-454. http://dx.doi.org/10.1086/209080

[19] Brucks, M. (1985) The Effects of Product Class Knowledge on Information Search Behavior. Vol. 12.

[20] Ajzen, I. and Fishbein, M. (1980) Understanding Attitudes and Predicting Social Behaviour. Prentice-Hall, Englewoods Cliffs.

[21] MNRT (2007) The National Wetlands Management Strategy. Dar es Salaam.

[22] Bollen, K.A. (1989) A New Incremental Fit Index for General Structural Equation Models. Sociological Methods \& Research, 17, 303-316. http://dx.doi.org/10.1177/0049124189017003004

[23] Browne, M. and Cudeck, R. (1993) Alternative Ways of Assessing Model Fit. In: Bollen, K.A. and Long, J.S., Eds., Testing Structural Equation Models, Sage, Newbury Park, 136162.

[24] Lai, C.J., Andrew, B., Chan, H. and Tao, J. (2002) Disposition towards Environmental Hazards in Hong Kong Chinese: Validation of a Chinese Version of Environmental Appraisal Inventory (EAI-C). Journal of Environmental Psychology, 23, 369-384.

http://dx.doi.org/10.1016/S0272-4944(02)00115-9

[25] Schultz, P.W., Gouveia, V.V., Cameron, L.D., Tankha, G., Schmuck, P. and Franek, M. (2005) Values and Their Relationship to Environmental Concern and Conservation Behaviour. Journal of Cross-Cultural Psychology, 36, 457-475. http://dx.doi.org/10.1177/0022022105275962

[26] Gautam, A.P. and Shivakoti, G.P. (2005) Conditions for Successful Local Collective Action in Forestry: Some Evidence from the Hills of Nepal. Society and Natural Resources, 8, 153 171. http://dx.doi.org/10.1080/08941920590894534 
[27] Ostrom, E. (2005) Understanding Institutional Diversity. Princeton University Press, Princeton.

[28] Agrawal, A. and Chhatre, A. (2006) Explaining Success in the Commons: Community Forest Governance in the Indian Himalaya. World Development, 34, 149-166.

http://dx.doi.org/10.1016/j.worlddev.2005.07.013

[29] Swanwick, C. (2009) Society's Attitudes to and Preferences for Land and Landscape. Land Use Policy, 26, 62-75. http://dx.doi.org/10.1016/j.landusepol.2009.08.025

[30] Robinson, J. (2004) Land Use Behavior of Private Landowners at the Urban/Rural Fringe. PhD Thesis, Ohio State University, Columbus.

Submit or recommend next manuscript to SCIRP and we will provide best service for you:

Accepting pre-submission inquiries through Email, Facebook, LinkedIn, Twitter, etc.

A wide selection of journals (inclusive of 9 subjects, more than 200 journals)

Providing 24-hour high-quality service

User-friendly online submission system

Fair and swift peer-review system

Efficient typesetting and proofreading procedure

Display of the result of downloads and visits, as well as the number of cited articles

Maximum dissemination of your research work

Submit your manuscript at: http://papersubmission.scirp.org/

Or contact jwarp@scirp.org 